\title{
PELUANG BISNIS ONLINE SITUS VOUCHER DISKON
}

\author{
Fransiscus Amonio Halawa ${ }^{*}$ \\ ${ }^{1}$ Pengajar Mata Kuliah Entrepreneurship, Universitas Bunda Mulia
}

\begin{abstract}
Discount voucher / voucher sites are one part of e-commerce. Rampant discount sites in Indonesia, a separate phenomenon, especially in terms of the development of Internet-based commerce (ecommerce). Discount voucher sites are sites or mobile apps that market advertisements about promos and discounts being held by companies into the world of the internet so that the spread becomes more widespread. With a discount voucher site, companies can advertise their promotions and discounts to the internet. The methodology of data collection is done by observation, namely: direct observation on various voucher and discount voucher sites in Indonesia and with Library Studies, reading books, articles and sites that can assist in the analysis. For marketing strategy done with Organic Marketing, that is by using SEO (Search Engine Optimization) Hash Tags, Meta Tags, Achor Links that must be applied into the website, outside of the side of the website, organic marketing can also be done by way of broadcasting and social media press. For offline marketing channels, discount voucher sites can be made by distributing flyers to public places, such as malls, to inform the public that there is a discount voucher Site presence that they can download using a smartphone. Business analysis is carried out by assessing business feasibility studies in terms of financial aspects. Based on the calculation of investment feasibility study, by using the method of payback period, net present value, internal rate of return, and profability index, it can be concluded that discount voucher sites deserve to be a business opportunity.
\end{abstract}

\section{Keywords : E-commerce, Discount Vouchers, Investment Feasibility Study}

\begin{abstract}
ABSTRAK
Situs kupon/voucher diskon merupakan salah satu bagian dari e-commerce. Merebaknya situs diskon di Indonesia, menjadi fenomena tersendiri terutama dalam hal perkembangan perdagangan berbasis internet (e-commerce). Situs voucher diskon merupakan situs atau aplikasi mobile yang memasarkan iklan-iklan mengenai promo dan diskon yang sedang diadakan oleh perusahaan-perusahaan ke dalam dunia internet sehingga penyebarannya menjadi semakin luas. Dengan adanya situs voucher diskon, perusahaan dapat mengiklankan promo dan diskon mereka ke internet. Metodologi pengumpulan data dilakukan dengan observasi, yaitu: pengamatan secara langsung pada situs-situs sejenis kupon dan voucher diskon yang ada di indonesia dan dengan studi pustaka, yaitu membaca buku-buku, artikel serta situs yang dapat membantu dalam analisa. Untuk strategi marketing dilakukan dengan organic marketing, yaitu dengan mengunakan SEO ( Search Engine Optimization) Hash Tags , Meta Tags , Achor Link yang harus diterapkan kedalam website tersebut, diluar dari sisi dalam website tersebut, organic marketing juga dapat dilakukan dengan cara broadcasting dan social media press. Untuk offline marketing channels, Situs voucher diskon dapat dilakukan dengan membagikan flyer ke tempat-tempat yang ramai masyarakat, seperti mall, untuk memberitahukan kepada masyarakat bahwa adanya kehadiran situs voucher diskon yang bisa mereka download menggunakan smartphone. Analisis bisnis dilakukan dengan penilaian studi kelayakan bisnis dari sisi aspek finansial. Berdasarkan hasil perhitungan studi kelayakan investasi, yaitu dengan menggunakan metode payback period, net present value, internal rate of return, dan profabilitas index, maka dapat disimpulkan bahwa situs voucher diskon layak untuk dijadikan sebagai peluang bisnis.
\end{abstract}

Kata Kunci: E-commerce, Voucher diskon, Studi kelayakan Investasi

*email: frans_halawa@yahoo.com 


\section{Latar Belakang}

\section{PENDAHULUAN}

Perkembangan teknologi informasi yang sangat pesat termasuk internet membawa dampak yang besar bagi segala aspek. Internet merupakan sarana elektronik yang dapat dipergunakan untuk berbagai aktivitas seperti komunikasi, riset, transaksi bisnis dan lainnya. Penggunaan layanan pembelian lewat internet (online shopping) di Indonesia juga meningkat drastis. Perubahan dramatis dalam bidang teknologi telah merubah cara hidup konsumen, cara belanja, dan berinteraksi dengan yang lainnya.

Pesatnya pertumbuhan global dalam perdagangan elektronik (ecommerce), mengakibatkan banyak bisnis mencoba untuk memperoleh keunggulan bersaing dengan menggunakan teknologi e-commerce dalam berinteraksi dengan para konsumen.

Banyaknya kemudahan dan kepraktisan dalam berbelanja online menjadi daya tarik tersendiri bagi konsumen. Konsumen yang semakin jeli terhadap berbagai pilihan yang ditawarkan sehingga mereka akan mencari informasi terlebih dahulu sebelum membeli suatu produk. Hal tersebut menjadikan persaingan antar perusahaan untuk mendapatkan pelanggan. Persaingan yang kompetitif membuat para perusahaan sekreatif mungkin memasarkan produknya supaya konsumen tertarik. Konsep pemasaran merupakan suatu proses sosial untuk mendapatkan apa yang dibutuhkan dengan menciptakan, menawarkan, dan menjualnya (Kotler dan Keller., 2009).

Berdasarkan hasil survei yang dilakukan oleh facebook pada saat pelaksanaan hari belanja online nasional (Harbolnas) diketahui bahwa terjadi peningkatan yang signifikan dalam transaksi e-commerce di Indonesia dimana dalam penelitian itu juga diperoleh informasi bahwa orang Indonesia lebih menyukai berbelanja secara online dengan menggunakan smartphone.

Hasil riset ICD memprediksi bahwa pasar e-commerce di Indonesia akan tumbuh 42\% dari tahun 2012-2015. Angka ini lebih tinggi jika dibandingkan negara lain seperti Malaysia (14\%), Thailand (22\%), dan Filipina $(28 \%)$ Tentulah nilai sebesar ini sangat menggoda bagi sebagian investor, baik dalam maupun luar negeri. Beberapa VC (Venture Capital) besar seperti Rocket Internet, CyberAgent, East Ventures,
IdeoSource, dan SoftBank bahkan sudah menanamkan modal ke perusahaan $e$ commerce yang berbasis di Indonesia.

Sebut saja beberapa diantaranya adalah raksasa Lazada dan Zalora, Berrybenka, Tokopedia, Bilna, Saqina, VIP Plaza, Ralali dan masih banyak lagi. Mereka adalah sebagian contoh dari perusahaan $e$ commerce yang sukses dan berhasil dalam memanfaatkan peluang pasar e-commerce di Indonesia yang meningkat signifikan.

Situs kupon/voucher diskon merupakan salah satu bagian dari $e$ commerce. Situs diskon sendiri adalah situs web diskon yang menampilkan sertifikat hadiah diskon yang dapat ditukarkan di perusahaan lokal ataupun nasional. Merebaknya situs diskon di Indonesia, menjadi fenomena tersendiri terutama dalam hal perkembangan perdagangan berbasis internet (e-commerce).

Situs voucher diskon atau kupon memiliki konsep yang sederhana. Pemilik situs kupon/voucher diskon sebagai penyedia jasa "iklan" produk melakukan penawaran kepada para pemilik produk untuk memasarkan produk mereka dengan harga yang lebih murah. Tujuan pemasaran harga lebih murah ini tidak lain untuk mengenalkan kepada calon pembeli tentang keberadaan produk mereka sebagai media promosi.

Jumlah anggota bisnis kupon dan voucher diskon terdaftarnya kini mencapai 35 juta di 150 kota di AS, dan di 100 kota lainnya di Eropa, Asia dan Amerika Selatan. Pendapatannya dari Januari 2010 hingga Januari 2011, diperkirakan pemasukan bulanannya melonjak 8 kali lipat dari US\$ 11 juta menjadi US\$ 89 juta, atau total US\$ 460 juta sepanjang 2010. Tahun 2016 ini pendapatannya diperkirakan meroket ke angka US\$ 3 miliar -4 miliar.

Kini ada sekitar 500 situs sejenis di seluruh dunia, termasuk 100 situs sejenis di negeri asalnya Amerika serikat. Di Indonesia sendiri kini terdapat sekitar 20 pemain sejenis, diantaranya Disdus.com, Dealkeren.com, Ogahrugi.com, eVoucher.co.id, Lapar.com, Grupay.com, Bursadiskon.net, dan lain-lain.

Terdapat beberapa masalah yang ditemukan pada beberapa situs kupon dan voucher diskon di Indonesia saat ini, diantaranya : Pertama, proses mendapatkan voucher diskon bukan sesuatu yang mudah karena biasanya diskon tersebut diberikan 
dalam waktu dan jumlah yang terbatas. Kedua, model transaksi yang dianggap kurang optimal karena masih menggunakan transfer rekening untuk melakukan transaksi pembelian kupon. Ketiga, pembatasan waktu penggunaan kupon atau voucher diskon hanya di hari atau jam tertentu saja. Keempat, tidak adanya fasilitas delivery. Kelima, produk dan jasa yang disediakan situs kupon dan voucher diskon di indonesia masih kurang beragam.

Mengingat adanya peluang yang besar dalam bisnis Kupon \& Voucher Diskon pada masa yang akan datang, maka penulis tertarik membahas peluang bisnis yang bergerak dibidang situs kupon dan voucher diskon.

\section{Metodologi Penelitian}

Metodologi yang digunakan adalah:

a. Metodologi pengumpulan data

1) Observasi, pengamatan secara langsung pada situssitus sejenis kupon dan voucher diskon yang ada di indonesia.

2) Studi Pustaka, dengan membaca buku-buku, artikel serta situs yang dapat membantu dalam analisa dan perancangan situs kupon dan voucher diskon.

b. Analisis bisnis

Analisis bisnis dilakukan dengan penilaian studi kelayakan bisnis dari sisi aspek finansial.

\section{HASIL DAN PEMBAHASAN \\ Analisa Pesaing}

Seperti produk-produk lainnya, situs voucher diskon juga memiliki pesaing utama dalam proses bisnis. Para pesaing tersebut merupakan Lakupon, Groupon Disdus dan ShopBack. Mereka juga merupakan situs yang memberikan informasi promo dan diskon yang diadakan perusahaan yang sedang terjadi di sekitar masyarakat.

\section{Lakupon}

Lakupon.com, salah satu website daily deals terbesar di Indonesia yang menawarkan berbagai promo voucher, promo diskon sampai dengan $90 \%$ serta promo produk dengan harga murah. Lakupon merupakan salah satu bisnis unit dari Emtek Group yang juga menaungi SCTV, Indosiar, O-channel, Liputan6, Vidio, dll.

Dapatkan Voucher Diskon Wisata, Diskon Restoran, Diskon Hotel, Paket Tour Murah, Paket Travel Murah yang sangat menarik. Tersedia juga berbagai produk pilihan mulai dari Barang Elektronik Murah, Promo Gadget, Fashion Pria Wanita, hingga Peralatan Rumah Tangga Murah lainnya. Untuk yang ingin berlibur dan berwisata bersama keluarga, ada banyak Paket Promo Wisata dalam Negeri, dan Paket Wisata Luar Negeri Murah hanya di Lakupon.com. Belanja Online Murah dan Mudah, Lakupon.com solusinya. Ada banyak penawaran kupon termurah yang bisa kamu pilih, seperti voucher restoran, produk makanan ringan, promo tiket masuk wahana, kupon perawatan kecantikan, produk kecantikan kosmetik hingga paket wisata ke indonesia dan luar negeri. Secara khusus, lakupon juga menyediakan voucher diskon untuk tiket masuk ke berbagai waterpark seperti Waterbom PIK Jakarta, Ancol, dan lain-lain.

Tak hanya memberikan harga promosi termurah, Lakupon juga senantiasa memberikan kemudahan untuk berbelanja online. Setelah menjadi member di Lakupon, Anda langsung bisa membeli berbagai voucher diskon promosi aneka kebutuhan dengan harga paling murah. Anda langsung bisa menikmati penawarkan menarik pilihan setelah menukarkan voucher sesuai syarat \& ketentuan yang tertera.

Lakukan juga pembayaran dengan banyak cara mudah, seperti internet banking, uang elektronik, kartu kredit, ATM otomatis, transfer bank dan indomaret. Untuk dapatkan newsletter info diskon, promosi terbaru dan termurah, Anda cukup dafartarkan diri menjadi member di Lakupon. Rasakan pengalaman berbelanja online voucher diskon di Lakupon dengan harga termurah setiap hari.

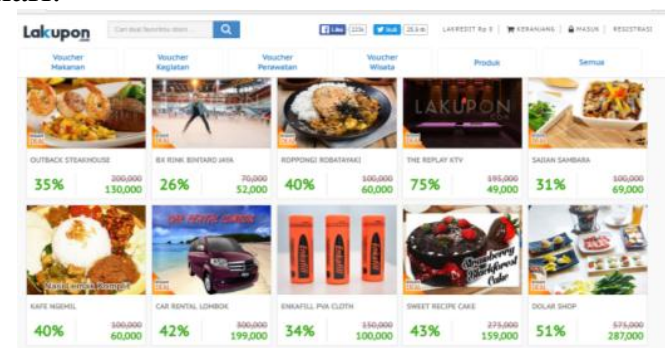

Gambar 1 Tampilan website Lakupon Sumber : https://lakupon.com 


\section{Groupon Disdus}

Groupon Indonesia, dikenal juga dengan nama Disdus, adalah toko online dan pusat diskon Indonesia yang menjual segala kebutuhan gaya hidup di dalam satu website. Dengan voucher diskon Groupon, Anda juga bisa membeli deal untuk restoran murah, promo hotel Jakarta, diskon perawatan salon, dan spa Jakarta. Deal makan murah yang dapat dibeli di Groupon antara lain adalah promo sushi, steak murah, promo pizza, Chinese Food murah, promo burger, dan promo buffet all you can eat murah. Tidak hanya itu, untuk yang gemar traveling dan ingin mengisi liburan murah berkualitas Groupon Disdus menyediakan promo hotel murah berbintang di berbagai kota seperti hotel Bandung, hotel Bali, serta promo waterpark dan diskon pusat rekreasi keluarga.

$$
\text { PT Disdus pertama kali }
$$
diperkenalkan oleh Jason Lamuda dan Ferry Tenka. Kedua founder PT Disdus ini mendapat inspirasi dari situs Groupon yang tengah berkembang pada tahun 2008 di Amerika Serikat. Melihat tingginya potensi dalam bisnis penyedia diskon, ide tersebut dibawa ke Indonesia dan pada tanggal 11 Agustus 2010 didirikanlah PT Disdus "Diskon Dahsyat Untuk Kita Semua". Konsep bisnis PT Disdus disebut dengan social commerce, yakni PT Disdus menjual berbagai penawaran dengan harga yang lebih murah, namun penjualannya dalam jumlah banyak, kurang lebih $1.000-2.000$ jenis barang dan jasa tiap minggunya. Terhitung dari April 2011, PT Disdus merupakan bagian dari perusahaan raksasa Groupon. Dilihat dari perspektif PT Disdus, pengakuisisian ini ditujukan untuk menambah modal sehingga dapat meningkatkan layanan dan penjualannya.

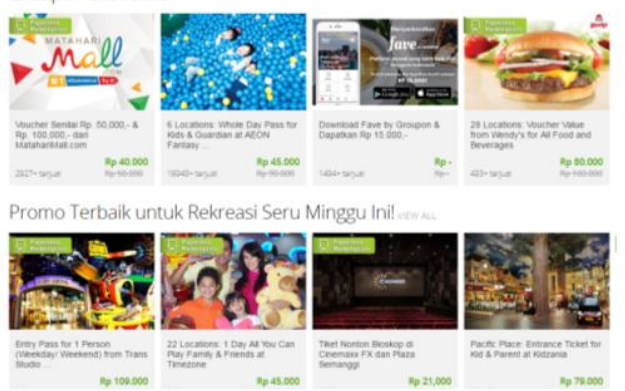

Gambar 3 Tampilan website Groupon Disdus Sumber : http://groupon.co.id

\section{ShopBack}

Didirikan pada tahun 2014, ShopBack adalah startup portal e-commerce dari Singapura yang memanfaatkan program komisi cashback. Hal ini memungkinkan pembeli online untuk mengambil kembali sebagian uang mereka ketika mereka membeli produk di e-commerce. Selain cashback, ShopBack juga memberikan promo, kupon diskon dan kode voucher untuk belanja online. Saat ini ShopBack telah merambah lima negara (Singapura, Malaysia, Filipina, Indonesia, dan India). ShopBack sudah berafiliasi secara resmi dengan lebih dari 300 e-commerce dari seluruh dunia termasuk Indonesia, seperti raksasa ritel online Lazada, Tokopedia, Bukalapak, Matahari Mall, eBay, Blibli, Tiket.com, Zalora, Groupon, AliExpress, Agoda, dsb.

ShopBack Indonesia melalui situs ShopBack.co.id telah berkomitmen untuk mendukung hasil karya anak bangsa Indonesia. ShopBack telah bekerja sama secara resmi dengan e-commerce lokal untuk menyediakan produk-produk dalam negeri yang berkualitas.

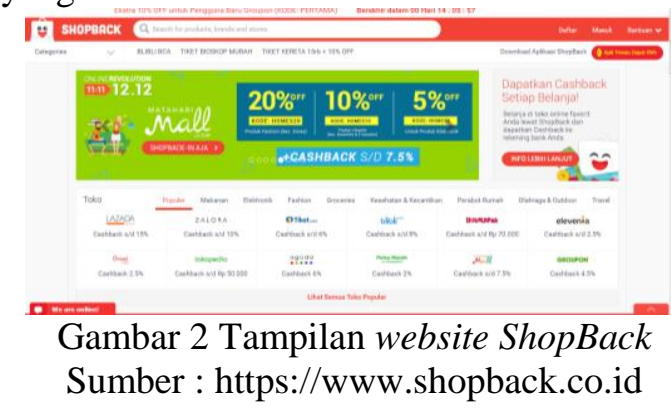

\section{Business Model Canvas}

Business model adalah formula untuk mencari keuntungan, sistem dari bisnis, dan sistem pembelajaran. Business model juga sebuah mekanisme dari perubahan ide menjadi pendapatan melalui biaya yang dapat diterima (Badden-Fuller \& Morgan, 2010:156). Business model canvas dibuat agar dapat menjalankan bisnis sesuai dengan yang diinginkan dan bergerak pada jalan yang benar. Karena bisnis ini merupakan bisnis $e$ commerce yang baru akan berjalan sehingga dibutuhkan gambaran proses bisnis dalam bentuk business model canvas yang dibuat menggunakan template dari Google Drive sebagai berikut: 


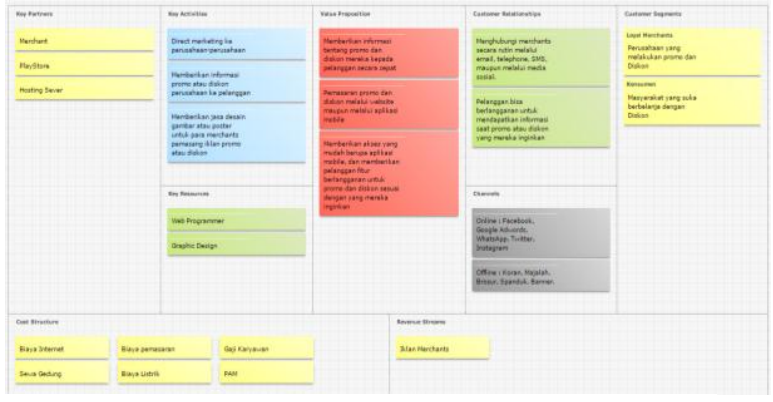

Gambar 4 Business Model Canvas Situs voucher diskon

\section{Customer Segments}

Customer segments adalah segmentasi pelanggan yang diincar oleh situs voucher diskon untuk dapat menjadi pelanggan mereka. Dari situs voucher diskon sendiri ada dua segmentasi pelanggannya, yaitu perusahaan yang ingin melakukan promo atau diskon lalu ingin memasarkan informasi promo atau diskon mereka, dan masyarakat yang suka untuk berbelanja atau yang mengincar promo atau diskon dari perusahaan-perusahaan.

\section{Value Propositions}

Value propositions merupakan nilai-nilai yang dapat diberikan oleh situs voucher diskon kepada perusahaan dan juga kepada pelanggan agar perusahaan dan pelanggan mendapatkan kepuasan dalam menggunakan aplikasi situs voucher diskon. Nilai-nilai yang diberikan situs voucher diskon pada perusahaan berupa memberikan wadah untuk perusahaan dapat memasarkan promo dan diskon yang ingin mereka lakukan, juga memberikan informasi tentang promo dan diskon mereka kepada pelanggan secara cepat.

Dengan nilai-nilai inilah situs voucher diskon memberikan perusahaan untuk memperbesar ruang lingkup pemasaran promo dan diskon mereka melalui website maupun melalui aplikasi mobile karena sudah banyak juga pelanggan yang menggunakan smartphone. Lalu nilai-nilai yang dapat diberikan pada pelanggan yaitu memberikan akses yang mudah berupa aplikasi mobile, dan memberikan pelanggan fitur berlangganan untuk promo dan diskon sesuai dengan yang mereka inginkan.

Bagi pelanggan dengan adanya situs voucher diskon ini mereka dapat mencari tahu informasi promo dan diskon yang sedang terjadi dimana saja dan kapan saja melalui smartphone mereka secara cepat dan muda, serta mereka akan diberitahu secara periodik mengenai informasi produk yang lagi promo atau diskon yang mereka inginkan melalui fitur berlangganan pada situs voucher diskon.

3. Customer Relationships

Customer relationships itu relasi yang dibangun oleh situs voucher diskon dengan perusahaan dan juga pelanggan sehingga situs voucher diskon dapat mengetahui apa yang dibutuhkan dan diinginkan oleh perusahaan dan pelanggan agar mereka mendapatkan kepuasan, dan juga membuat perusahaan dan pelanggan setia dalam menggunakan jasa situs voucher diskon atau menjadi konsumen jangka panjang. Situs voucher diskon selalu berusaha menjaga hubungan yang baik dengan para perusahaan pemasang iklan Diskon dan promo, dengan menghubungi merchants secara rutin melalui email, telephone, SMS, maupun melalui media sosial. Selain itu pelanggan juga bisa berlangganan untuk mendapatkan informasi saat promo atau diskon yang mereka inginkan.

\section{Revenue Stream}

Revenue stream adalah aliran pemasukan situs voucher diskon dari hasil proses bisnisnya yang dapat menjadi keuntungan bagi situs voucher diskon. Revenue stream dari situs voucher diskon sendiri yaitu iklan promo dan diskon yang ingin dipasarkan oleh perusahaan dalam situs situs voucher diskon.

\section{Key Activities}

Key activities adalah aktivitas-aktivitas utama dari situs voucher diskon itu sendiri untuk menjalankan proses bisnisnya. Aktivitas-aktivitas tersebut meliputi pemasaran terhadap situs voucher diskon, direct marketing ke perusahaan-perusahaan, mendesain iklan promo atau diskon tersebut, dan memberikan informasi promo atau diskon perusahaan ke pelanggan. Pemasaran yang dilakukan untuk situs voucher diskon berupa iklan secara online maupun offline.

Iklan secara online termasuk iklan dalam Facebook dan melalui Google Adwords, sedangkan iklan secara offline menggunakan flyer yang disebarkan ke tempat yang ramai dengan orang dan iklan di surat kabar. Adapun direct marketing ke perusahaan adalah usaha pemasaran situs voucher diskon yang langsung menghampiri perusahaanperusahaan agar mereka mengetahui lebih dalam tentang situs voucher diskon.

Situs voucher diskon juga memberikan jasa desain gambar atau poster untuk informasi promo atau diskon yang ingin 
mereka masukan dalam situs voucher diskon sehingga mereka cukup memberikan detailnya untuk dapat mengiklankan di situs voucher diskon.

Terakhir merupakan aktivitas yang paling utama dari situs voucher diskon, yaitu mengiklankan promo atau diskon perusahaanperusahaan tersebut agar dapat dilihat oleh pelanggan sehingga mereka dapat mengetahui informasi promo atau diskon apa saja yang sedang terjadi disekitar mereka.

\section{Key Partners}

Key partners merupakan jaringan antar perusahaan yang dapat saling membantu dan saling mendukung proses bisnis mereka. Situs voucher diskon berusaha menjalin hubungan key partners dengan perusahaan yang memberi informasi iklan, Android playstore, dan hosting server.

Perusahaan yang memberi informasi iklan merupakan key partner yang sangat vital karena dengan adanya iklan dari merekalah agar situs voucher diskon dilihat oleh pelanggan, begitu pula dengan perusahaan tersebut, dengan bekerja sama dengan situs voucher diskon maka mereka dapat mengiklankan informasi promo atau diskon mereka.

Sedangkan android playstore merupakan key partner untuk meluncurkan aplikasi situs voucher diskon, dan hosting server untuk menjaga server dari situs voucher diskon berjalan dengan baik.

\section{Key Resources}

Key resources merupakan sumber utama yang dapat membantu situs voucher diskon dalam menjalankan bisnisnya. Key resources dari situs voucher diskon yaitu desainer untuk membuat desain poster atau gambar dari informasi promo dan diskon yang diberikan perusahaan yang dibuat menarik agar dapat memberikan informasi yang jelas pada pelanggan. Web Programer yang merancang situs situs voucher diskon.com.

\section{Channels}

Channels itu sebuah jaringan yang dapat membuat situs voucher diskon tersebar luas dan dapat menyampaikan nilai-nilai yang dapat diberikan oleh situs voucher diskon kepada perusahaan dan juga pelanggan.

Terdapat dua channels yang dimiliki oleh situs voucher diskon, yaitu online, dimana situs voucher diskon menggunakan internet seperti Facebook dan Google Adwords untuk mengiklankan situs voucher diskon agar diketahui masyarakat, juga offline, dimana situs voucher diskon menggunakan word-ofmouth, yaitu memberitahukan pada satu atau lebih orang agar mereka membicarakan dengan teman, kolega, keluarga, atau orangorang terdekat mereka, juga dapat menggunakan iklan di surat kabar atau flyer yang disebarkan di tempat ramai.

\section{Cost Structure}

Cost structure adalah rincian pengeluaran yang sudah dilakukan oleh situs voucher diskon dalam pembuatan aplikasi situs voucher diskon itu sendiri dan biaya yang dikeluarkan dalam menjalankan proses bisnis dari situs voucher diskon. Cost structure dari situs voucher diskon berupa biaya internet untuk menjalankan aplikasi situs voucher diskon, biaya android playstore untuk meluncurkan aplikasi mobile situs voucher diskon, biaya marketing situs voucher diskon untuk memasarkan situs voucher diskon kepada pelanggan, dan biaya lain-lainnya.

\section{Strategi Pemasaran}

Menurut Shaw, Eric (2012), ada kerangka kerja untuk strategi pemasaran, salah satunya adalah strategi pengenalan pasar dimana disebutkan "Pada pengenalan, ahli strategi pemasaran memiliki dua prinsip strategi untuk dipilih: penetrasi atau niche". Situs voucher diskon akan memilih untuk melakukan penetrasi dimana situs voucher diskon akan melakukan pendekatan langsung kepada perusahaan-perusahaan untuk memberitahu mereka bahwa terdapat website kupon/voucher diskon yang dapat memasarkan promo atau diskon yang ingin mereka lakukan. Dengan begitu perusahaan tahu bahwa mereka dapat memasarkan promosi mereka tidak hanya melalui surat kabar ataupun televisi tapi juga melalui internet.

Dari marketing channels pun terdapat dua jenis pemasaran yang dapat dilakukan, yaitu online dan offline marketing channels. Situs voucher diskon akan melakukan keduanya agar website kupon/voucher diskon situs voucher diskon ini dapat diketahui oleh masyarakat luas dan mulai melakukan download aplikasi mobile situs voucher diskon sehingga perusahaan-perusahaan akan percaya bahwa sudah banyak masyarakat yang sudah memiliki aplikasi mobile situs voucher diskon. 
IT startup fokus akan 2 hal system marketing , yaitu Organic dan Non Organic Marketing , Organic Marketing mengunakan SEO ( Search Engine Optimization) Hash Tags , Meta Tags, Achor Link yang harus diterapkan kedalam website tersebut, diluar dari sisi dalam website tersebut, organic marketing juga dapat dilakukan dengan cara broadcasting dan social media press. menentukan media digital seperti apa yang efektif untuk digunakan (Altstiel \& Grow, 2010).

1. Strength (Kekuatan)

A. Memiliki segment pasar yang lebih luas

B. Memberikan Payback return ke merchant yang lebih pendek agar merchant mendapatkan benefit dan profit margin yang sesuai dengan perputaran usaha masing-masing merchant

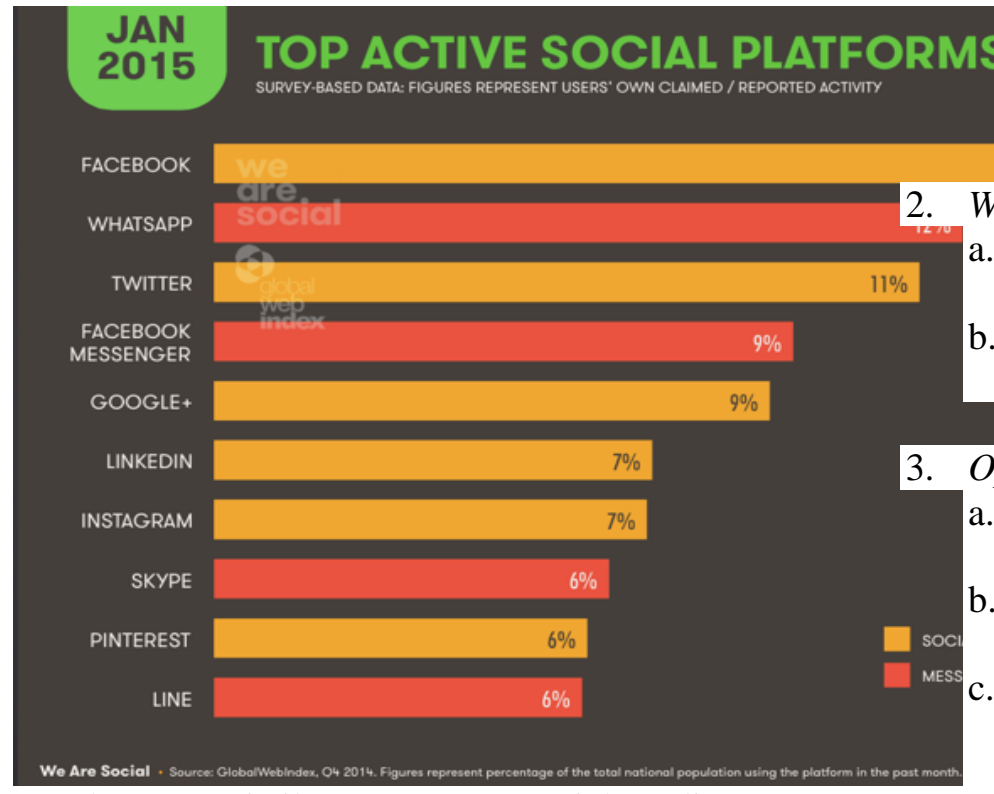

Weakness (Kelemahan)

. Situs voucher diskon ini masih baru dibanding yang sudah ada

b. Masih sedikit yang tahu situs situs voucher diskon ini

Opportunity (Kesempatan)

a. Dengan jaringan internet cakupan pemasaran semakin luas

b. Memberikan layanan pemasaran gratis pada awal pemasaran

. Promo atau diskon dari perusahaan pasti selalu ada dengan waktu tertentu

4. Thread (Ancaman)

Di Indonesia

Sumber: GlobalWebIndex (2016)

Untuk offline marketing channels, situs voucher diskon disarankan untuk pergi ke tempat-tempat yang ramai masyarakat, seperti mall, untuk memberitahukan kepada masyarakat bahwa adanya kehadiran situs voucher diskon yang bisa mereka download menggunakan smartphone mereka dengan membagikan flyer atau menjelaskan secara langsung kepada mereka yang ingin tahu lebih dalam. Situs voucher diskon juga disarankan memasangkan iklan di koran agar semakin besar kemungkinan masyarakat mengetahui keberadaan website kupon/voucher diskon situs voucher diskon ini.

\section{Analisis SWOT}

Analisa SWOT (Strength, Weakness, Opportunity, dan Thread) berguna untuk mengevaluasi dan mencari tahu faktor internal-eksternal, baik yang mendukung maupun kurang mendukung bagi website kupon/voucher diskon situs voucher diskon ini. Analisa SWOT juga dipakai untuk a. Pesaing baru terus berkembang dan berdatangan

b. Belum banyak situs seperti ini, pesaing dapat datang dengan mudah

\section{Studi Kelayakan Bisnis Aspek Keuangan}

Studi kelayakan dari aspek finansial dapat diteliti dari penilaian aliran kas dari suatu investasi. Metode yang digunakan dalam penilaian aliran kas suatu investasi adalah: 1) metode payback period, 2) net present value, 3) internal rate of return, dan 4) profabilitas index menurut Suliyanto (2010:195).

\section{Perhitungan Payback Periode}

Metode payback period adalah perhitungan atau penentuan jangka waktu yang dibutuhkan untuk menutup initial investment dari suatu proyek dengan menggunakan cash inflow yang dihasilkan oleh proyek tersebut. Cash inflow (arus kas masuk bersih) atau yang sering dikenal dengan istilah proceeds adalah laba setelah pajak ditambah dengan biaya penyusutan.

Waktu yang disaratkan $=5$ tahun. 
Payback Period = Kurang dari 1 Tahun. Berdasarkan data diatas investasi layak karena PP > waktu yang disaratkan.

Perhitungan Average Rate of Return (ARR) Metode Average Rate of Return (ARR) merupakan metode yang digunakan untuk mengukur tingkat keuntungan yang diperoleh dari suatu investasi. Dari perhitungan di atas didapatkan bahwa nilai ARR sebesar 2773\%, sedangkan tingkat pengembalian yang diharapkan sebesar 20\%. Berdasarkan metode penilaiaan kelayan investasi menggunakan ARR, Jika ARR > tingkat pengembalian yang diharapkan, maka investasi layak.

\section{Perhitungan Net Present Value (NPV)}

Metode Net Present Value (NPV) merupakan metode yang dilakukan dengan cara membandingkan nilai sekarang (present value) dari aliran kas masuk bersih (proceeds) dengan nilai sekarang dari biaya pengeluaran suatu investasi (outlays).

Dari hasil perhitungan di atas, dapat diketahui bahwa nilai NPV positif sebesar Rp $\mathbf{3 , 8 5 7 , 3 2 5 , 0 0 4 . 4 4}$, Berdasarkan metode penilaian kelayakan investasi NPV $>0$, maka investasi yang dilakukan memberikan manfaat bagi perusahaan. Sehingga dapat disimpulkan bisnis ini layak untuk dijalankan.

\section{Perhitungan Profitability Index (PI)}

Profitability Index (PI) atau sering disebut dengan Desirability Index (DI) merupakan metode menghitung perbandingan antara nilai sekarang penerimaan kas bersih di masa yang akan datang (proceeds) dengan nilai sekarang investasi (outlays).

Dari hasil perhitungan diatas didapatkan $\mathrm{PI}=78.15$. Berdasarkan kriteria investasi bila PI > dari 1, maka investasi layak.

\section{Rangkuman Penilaian Kelayakan Investasi Tabel 1}

Rangkuman Penilaian Kelayakan Investasi

\begin{tabular}{|l|l|l|}
\hline $\begin{array}{c}\text { Penilaian } \\
\text { Kelayakan } \\
\text { Investasi }\end{array}$ & \multicolumn{1}{|c|}{ Hasil } & \multicolumn{1}{c|}{ Keterangan } \\
\hline & & $\begin{array}{l}\text { Waktu yang } \\
\text { disaratkan = 5 tahun. } \\
\text { Payback Periode }\end{array}$ \\
$\begin{array}{l}\text { Payback } \\
\text { Period (PP) }\end{array}$ & $\begin{array}{l}\text { Kurang dari 1 } \\
\text { Tahun }\end{array}$ & $\begin{array}{l}\text { Kurang dari 1 tahun. } \\
\text { Berdasarkan data } \\
\text { diatas investasi layak } \\
\text { karena PP > waktu } \\
\text { yang disaratkan }\end{array}$ \\
& & Dari hasil \\
\hline Average & $\mathbf{2 7 7 3 \%}$ & \\
\hline
\end{tabular}

\begin{tabular}{|c|c|c|}
\hline $\begin{array}{l}\text { Rate of } \\
\text { Return } \\
(\text { ARR })\end{array}$ & & $\begin{array}{l}\text { perhitungan diatas } \\
\text { didapatkan bahwa } \\
\text { ARR sebesar 2773\%. } \\
\text { Tingkat } \\
\text { pengembalian yang } \\
\text { diharapkan = 20\% } \\
\text { Berdasarkan metode } \\
\text { penilaian kelayakan } \\
\text { investasi } \\
\text { menggunakan ARR, } \\
\text { bila ARR > tingkat } \\
\text { pengembalian yang } \\
\text { diharapkan maka } \\
\text { investasi layak. }\end{array}$ \\
\hline $\begin{array}{l}\text { Net Present } \\
\text { Value } \\
(N P V)\end{array}$ & $\begin{array}{l}\text { Rp } \\
\mathbf{3 , 8 5 7 , 3 2 5 , 0 0 4 . 4 4}\end{array}$ & $\begin{array}{l}\text { Dari hasil } \\
\text { perhitungan diatas, } \\
\text { dapat diketahui } \\
\text { bahwa nilai NPV } \\
\text { positif sebesar Rp } \\
3,857,325,004.44, \\
\text { Berdasarkan metode } \\
\text { penilaian kelayakan } \\
\text { investasi NPV > } 0 \text {, } \\
\text { maka investasi layak. }\end{array}$ \\
\hline $\begin{array}{l}\text { Profitability } \\
\text { Index (PI) }\end{array}$ & 78.15 & $\begin{array}{l}\text { Dari hasil } \\
\text { perhitungan diatas } \\
\text { didapatkan PI = } \\
78.15 \text {. } \\
\text { Berdasarkan kriteria } \\
\text { investasi bila PI > } \\
\text { dari 1, maka } \\
\text { investasi layak }\end{array}$ \\
\hline
\end{tabular}

Sumber: Peneliti (2018)

\section{SIMPULAN}

Situs voucher diskon merupakan situs atau aplikasi mobile yang memasarkan iklan-iklan mengenai promo dan diskon yang sedang diadakan oleh perusahaan-perusahaan ke dalam dunia internet sehingga penyebarannya menjadi semakin luas. Dengan adanya situs voucher diskon, perusahaan dapat mengiklankan promo dan diskon mereka ke internet dalam bentuk aplikasi mobile sehingga dapat diakses oleh pelanggan yang sudah menggunakan internet dengan smartphone mereka.

Berdasarkan hasil perhitungan studi kelayakan investasi, yaitu dengan menggunakan metode payback period, net present value, internal rate of return, dan profabilitas index, maka dapat disimpulkan bahwa situs voucher diskon layak untuk dijadikan sebagai peluang bisnis. 


\section{DAFTAR PUSTAKA}

Altstiel, Tom and Jean Grow (2010). Advertising creative: Strategy, copy \& design. Thousand Oaks, CA: Sage.

Baden-Fuller, C., \& Morgan, M. (2010). Business Models. Long Range Planning

Kotler dan Keller. 2009. Manajemen Pemasaran. Jilid I. Edisi ke 13. Jakarta: Erlangga

Shaw, Eric H. (2012). Marketing strategy from the origin of the concept to development of a conceptual framework. Journal of Historical Research in Marketing Vol.4.no.1, 2012. pp.30-55.

Suliyanto. (2010), Studi Kelayakan Bisnis: Pendekatan Praktis, Andi Offset, Yogyakarta. 